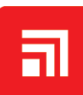 CHITKARA \\ Journal of Nuclear Physics, Material Sciences, Radiation and Applications

\section{Mini Subcritical Nuclear Reactor}

\author{
Hector Rene Vega-Carrillo*1, V. P. Singh ${ }^{2}$, Claudia Rafela Escobedo-Galván ${ }^{3}$, Diego Medina Castro ${ }^{1,4}$, Arturo Agustin Ortiz Hernandez ${ }^{5}$, \\ Teodoro Rivera-Montalvo ${ }^{6}$ and Segundo Agustín Martínez-Ovalle ${ }^{7}$ \\ ${ }^{1}$ Academic Unit of Nuclear Studies of the University Autonomous of Zacatecas C. Cipres 10, Fracc. La Peñuela, Zacatecas, Zac. \\ Mexico \\ ${ }^{2}$ Karanatak University, Dharwad, Karnataka-580001, India \\ ${ }^{3}$ Center of Scientific and Technological Studies No 18, Blvd. del Bote s/n. Cerro del Gato, Ejido la Escondida. 98160 Zacatecas, Zac. \\ Mexico \\ ${ }^{4}$ National Institute of Nuclear Research, Carretera México Toluca-La Marquesa s/n, 52750 Ocoyoacac, Estado de México. Mexico \\ ${ }^{5}$ Polytechnic University of Zacatecas, Plan de Pardillo s/n. Zona Industrial. Fresnillo, Zac. Mexico \\ ${ }^{6}$ Research Center in Applied Science and Advanced Technology-IPN Legaria unit, Av. Legaria 694, Col. Irrigación. 11500 Ciudad de \\ Mexico. Mexico \\ ${ }^{7}$ Pedagogical and Technological University of Colombia, Tunja-150003, Colombia
}

*Email: fermineutron@yahoo.com

\section{ARTICLE INFORMATION}

Received: January 27, 2019

Revised: February 14, 2019

Accepted: February 16, 2019

Published online: February 26, 2019

Keywords:

Subcritical nuclear reactor, Nuclear Chicago,

Monte Carlo, Neutron spectrum, keff

DOI: $10.15415 /$ jnp.2019.62026

\begin{abstract}
A mini subcritical nuclear reactor was designed using Monte Carlo methods. The reactor has light water as moderator, natural uranium as fuel, and a ${ }^{239} \mathrm{PuBe}$ neutron source. In the design uranium fuel was modeled in an arrangement of concentric rings: 8.5, 14.5, $20.526 .5,32.5 \mathrm{~cm}$-inner radius, $3 \mathrm{~cm}$-thick, and $36 \mathrm{~cm}$-high. Different models were made from a single ring of natural uranium to five rings. For each case, the neutron spectra, the neutron fluence distribution, the effective multiplication factor, the amplification factor, and the reactor power were estimated. The ambient dose equivalent rate outside the mini reactor was also estimated. The maximum value for the $\mathrm{k}_{\text {eff }}(0.78)$ was obtained when five rings of fuel were used; this value is close to 0.86 which belongs to a Nuclear Chicago subcritical reactor which requires almost twice the amount of uranium than the mini subcritical reactor.
\end{abstract}

\section{Introduction}

Nuclear energy is a reliable option for worldwide energy supply, also is a good option to mitigate the greenhouse gas emissions; however, it is perceived as risky energy source [1].

Some developed countries like Japan, Germany, Switzerland, etc. are limiting their expansion on nuclear power production. On the other hand, countries like India and China are increasing the nuclear power plants construction due to the energy demand combined with the shortage of fossil fuels and the limits on greenhouse gas emissions [2]. In the case of countries in Latin America, nuclear energy production is very small, however expectations of increase its participation are promising.

Most countries meet their energy demands based on fossil fuel consumption, contributing to global warming through the emission of gases such as sulfur dioxide, nitrogen oxides and carbon dioxide. To avoid this has been used the sources of alternative energy such as wind, hydraulic, solar and nuclear energy etc. But none of these, in isolation, can completely satisfy the energy demand. Worldwide there are 447 nuclear power plants in operation and 287 new will be on line by $2035[3,4]$. There are many ways to classify nuclear reactors, in terms of their application nuclear reactors are classified as [5],

- Power reactors that are used to produce electric energy, through the nuclear fission chain reaction induced by neutrons in a multiplied medium. Commercially reactors are designed to produce electric power of 600 and $1500 \mathrm{MWe}$ with thermodynamic efficiencies close to $33 \%$ [5].

- Research reactors are used in several applications and to carry on scientific research. This type of reactors becomes a source of neutrons that are used in the analysis of materials by neutron activation analysis or 
to produce radionuclides being used in medicine and in industry. The power of these reactors varies from a few Watts to almost $100 \mathrm{MW}$ [6-8].

- Teaching reactors, which are normally subcritical meaning that the nuclear fission chain reaction occurs only with an external neutron sources; as soon this source is withdrawn or it is switch off the reactor is shutdown. This type of reactor are easy and safe to operate [7-10].

Subcritical reactors are used to perform experiments that confirm calculations of power reactors, and are also being used to transmute some radionuclides in nuclear waste $[10,11]$. The most important parameters of a reactor are: the multiplication factor $\left(\mathrm{k}_{\mathrm{eff}}\right)$, the reactivity, the spatial distribution of neutrons, the neutron spectra inside and outside the reactor core and the ambient dose equivalent outside the reactor $[12,13]$.

The $\mathrm{k}_{\text {eff }}$ is the ratio between the neutron density present in the $i^{\text {th }}+1$ generation and the neutron density present in the $\mathrm{i}^{\text {th }}$ generation. If $\mathrm{k}_{\text {eff }}>1$, the reactor is supercritical, if, $\mathrm{k}_{\text {eff }}=1$ the reactor is critical, and if $\mathrm{k}_{\text {eff }}<1$ the reactor is subcritical [14]. Subcritical reactors are designed to remain subcritical regardless of any situation like flooding or if the external neutron source is left inside [15].

In Mexico there are two subcritical assemblies, one in the Instituto Politecnico Nacional (IPN) in Mexico City and the second one is in the Universidad Autonoma de Zacatecas (UAZ). Both reactors are Nuclear Chicago model 9000 which is a heterogeneous reactor using light water as moderator, and natural uranium as fuel. Moderator and fuel are contained into a $121.92 \mathrm{~cm}$-diameter and $152.4 \mathrm{~cm}$ height stainless steel cylinder. Nuclear fuel is distributed into a hexagonal array in whose center is inserted an isotopic neutron source to start-on the reactor. The neutron source is a $1.01 \mathrm{E}(7) \mathrm{s}^{-1}{ }^{239} \mathrm{PuBe}[16]$. With all fuel elements (2.43 tons of uranium) the $\mathrm{k}_{\mathrm{eff}}$ is 0.8268 , having an amplification factor $\mu=5.77$, the reactor power is $0.617 \mathrm{~mW}$, the maximum neutron flux is $\phi_{\text {Máx }}=2.93 \mathrm{E}(4) \mathrm{cm}^{-2}-\mathrm{s}^{-1}$. The ambient dose equivalent outside the stainless steel container is 14 microSv/h [7].

The design of nuclear reactor can be carried out using deterministic or Monte Carlo methods. The deterministic methods are used for calculations of critical reactors, these methods are approximations of the Boltzmann equation, like the multi-group diffusion theory [17-19].

The objective of this work was to use Monte Carlo methods in order to design a subcritical mini nuclear reactor with natural uranium fuel, moderator of light water and a neutron isotope source of ${ }^{239} \mathrm{Pu}-\mathrm{Be}$, and to compare this design with the Nuclear Chicago, model 9000, subcritical reactor.

\section{Materials and Methods}

This work was carrying out with the Monte Carlo code MCNP5 and the cross section library ENDF/VI [20]. The reactor was designed modeling the nuclear fuel concentric rings, as is shown in Figure 1.

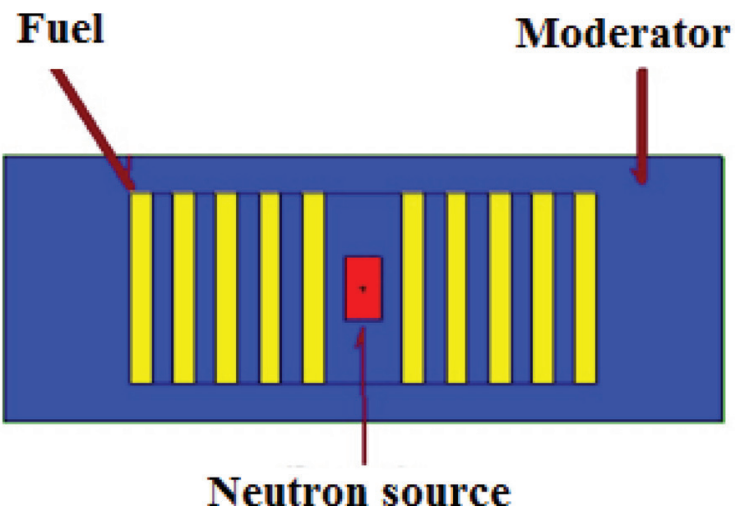

Figure 1: Side view of nuclear reactor model with five rings of uranium.

Figure 1 shows the reactor model with five fuel rings, in the center is the ${ }^{239} \mathrm{PuBe}$ source, and the moderator is light water. Five cases were designed having 8.5, 14.5, 20.5 26.5, and $32.5 \mathrm{~cm}$-inner radius, each fuel ring is $3 \mathrm{~cm}$-thick, and $36 \mathrm{~cm}$-high.

The Monte Carlo method was used to calculate the effective multiplication factor, $\mathrm{k}_{\mathrm{eff}}$, that was used to calculate the neutron amplification factor, $\mu$, using equation 1 .

$$
\mu=\frac{1}{1-k_{e f f}}
$$

Also the spatial distribution of the neutrons and the ambient dose equivalent was estimated, as well as the neutron spectra along the radius for reactor with one, two, three, four, and five fuel rings. With the $\mathrm{k}_{\text {eff }}$ and the $\mu$ values the reactor power was calculated using equation 2 .

$$
P=\frac{Q \mu k_{e f f}}{v p f}
$$

In equation (2), $\mathrm{Q}$ is the neutron source strength $1.01 \mathrm{E}(7)$ $\mathrm{n} / \mathrm{s}, \nu=2.44 \mathrm{n} /$ fission, and $\mathrm{p}_{\mathrm{f}}=3.20077 \mathrm{E}(10)$ fissions $/$ Watt.

Monte Carlo calculations were also used to estimate the neutron spectra to different distances in the reactor for the ${ }^{239} \mathrm{PuBe}$ source, and the reactor with $1,2,3,4$, and 5 rings of fuel (RF).

The ambient dose equivalent rate was calculated to 51 $\mathrm{cm}$ using the neutron fluence-to-ambient dose equivalent coefficients from the ICRP 74 [21]. 


\section{Results and Discussion}

In table 1 are shown the values of fuel mass, $\mathrm{k}_{\mathrm{eff}}$, amplification factor $(\mu)$, reactor power, and the ambient dose equivalent rate
$\mathrm{H}^{*}(10)$ in function of the amount of reactor fuel rings and when in the reactor center is inserted ${ }^{239} \mathrm{PuBe}$ source emitting $1.01 \mathrm{E}(7)$ $\mathrm{n} / \mathrm{s}$. The $\mathrm{H}^{*}(10)$ values are to $51 \mathrm{~cm}$ from the center (this is $1 \mathrm{~cm}$ outside the reactor surface).

Table 1: $\mathrm{k}_{\mathrm{eff}}$, fuel mass, $\mu$, reactor power and $\mathrm{H}^{*}(10)$ for reactor with different fuel rings.

\begin{tabular}{llllll}
\hline $\begin{array}{l}\text { Rings } \\
\text { of fuel }\end{array}$ & $\begin{array}{l}\text { Fuel mass } \\
{[\mathbf{k g}]}\end{array}$ & $\mathbf{k}_{\mathrm{eff}}$ & $\boldsymbol{\mu}$ & $\begin{array}{l}\text { Power } \\
{[\mathbf{m W}]}\end{array}$ & $\begin{array}{l}\mathbf{H}^{*}(\mathbf{1 0})(\mathbf{5 1} \mathbf{~ c m}) \\
{[\boldsymbol{\mu S \mathbf { S v }}]}\end{array}$ \\
\hline \pm & 90.7 & $0.5298 \pm 3.494 \mathrm{E}(-4)$ & 2.13 & 0.27 & $13.4 \pm 4.2 \%$ \\
2 & 259.2 & $0.6530 \pm 6.610 \mathrm{E}(-4)$ & 2.79 & 0.43 & $14.4 \pm 5.7 \%$ \\
3 & 505.5 & $0.7186 \pm 5.617 \mathrm{E}(-4)$ & 3.70 & 0.63 & $18.3 \pm 5.3 \%$ \\
4 & 829.5 & $0.7585 \pm 5.648 \mathrm{E}(-4)$ & 4.42 & 0.79 & $29.4 \pm 3.9 \%$ \\
5 & 1229.2 & $0.7819 \pm 5.763 \mathrm{E}(-4)$ & 5.01 & 0.93 & $53.0 \pm 3.25 \%$ \\
\hline
\end{tabular}

The $\mathrm{k}_{\text {eff }}, \mu$ and the reactor power increases as the amount of fuel is added. The increase of $\mathrm{k}_{\text {eff }}$ with fuel mass has the same shape reported for a Nuclear Chicago subcritical reactor. In the case with 5 rings of fuel the $\mathrm{k}_{\text {eff }}$ is 0.7819 the total mass of uranium is $1229 \mathrm{~kg}$, this reactor is a $50 \mathrm{~cm}$-radius and 50 cm-height cylinder.

The $\mathrm{k}_{\text {eff }}$ of a Nuclear Chicago subcritical reactor is 0.8268 which is $5.7 \%$ larger than the $\mathrm{k}_{\text {eff }}$ of our mini reactor. This difference is small considering that the Nuclear Chicago subcritical reactor requires $2430 \mathrm{~kg}$ of fuel that is inside a $61 \mathrm{~cm}$-radius and $152 \mathrm{~cm}$-height cylinder. The amount of fuel of Nuclear Chicago subcritical reactor is almost twice (1.977) the amount of fuel of mini subcritical reactor.

The volume of Nuclear Chicago subcritical reactor is 4.525 times larger than the mini subcritical reactor.

The amplification factor of Nuclear Chicago subcritical reactor is 5.77 being $15.2 \%$ larger than $\mu$ in the mini subcritical reactor. On the other hand the reactor power of mini subcritical reactor is $0.93 \mathrm{~mW}$ which is $50.7 \%$ larger that the power of Nuclear Chicago subcritical reactor.

Outside the reactor $(1 \mathrm{~cm}$ form the external surface of reactor) the ambient dose equivalent rate in the mini subcritical reactor is $53 \mathrm{microSv} / \mathrm{h}$ which is 3.8 times larger than the $\mathrm{H}^{*}(10)$ in the Nuclear Chicago subcritical reactor; this difference is probably due to the reactor size.

In figures 2, 3, 4, 5, and 6 are shown the neutron spectra to $3.8,10,20,30$, and $40 \mathrm{~cm}$ from the neutron source center along the radius respectively. Neutron spectra are for cases where there is only the neutron source (no fuel), and when the rings of fuel (RF) are added.

In figure 2 are the neutron spectra to $3.8 \mathrm{~cm}$-radius and in the middle point along $\mathrm{z}$-axis. The bare ${ }^{239} \mathrm{PuBe}$ isotopic neutron source produce neutrons from 0.5 up to $11.5 \mathrm{MeV}$, to $3.8 \mathrm{~cm}$ inside a light water moderator epithermal and thermal neutrons are produced due to the moderation and thermalization process. To $3.8 \mathrm{~cm}$ the neutron spectra have the same shape but the amount of neutrons increases as the fuel rings are added. The spectra have a small peak of thermal neutrons $(\mathrm{E}<4 \mathrm{eV})$ and a larger peak of fast neutrons $(0.1$ $<\mathrm{E}<20 \mathrm{MeV})$ linked by epithermal neutrons $(4 \mathrm{E}(-7)<$ $\mathrm{E}<0.1 \mathrm{MeV})$.

In figure 3 are the neutron spectra to $10 \mathrm{~cm}$ from the reactor center, which is the moderator located between the first and the second fuel ring.

To $10 \mathrm{~cm}$ the impact of neutron multiplication due to nuclear fissions is larger than at $3.8 \mathrm{~cm}$. Bare source has the largest amount of thermal neutrons in comparison to spectra produced when ring fuels are added; this is due to the capture of thermal neutrons in the fuel. As the RF are included the fast neutrons are shifted to the left where the larger peak is for 0.5 to $1 \mathrm{MeV}$, while the bare source has its largest peak in 2 to $3.5 \mathrm{MeV}$ neutrons.

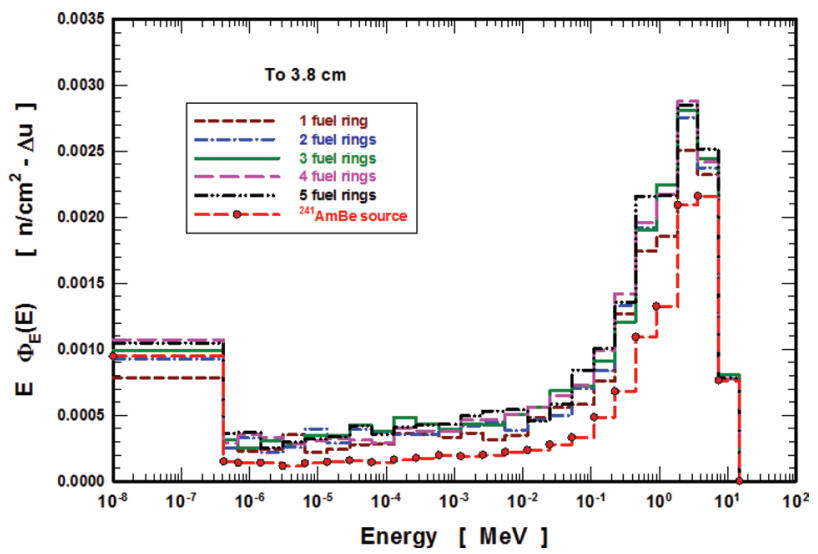

Figure 2: Neutron spectra, per history, to $3.8 \mathrm{~cm}$ from the center 


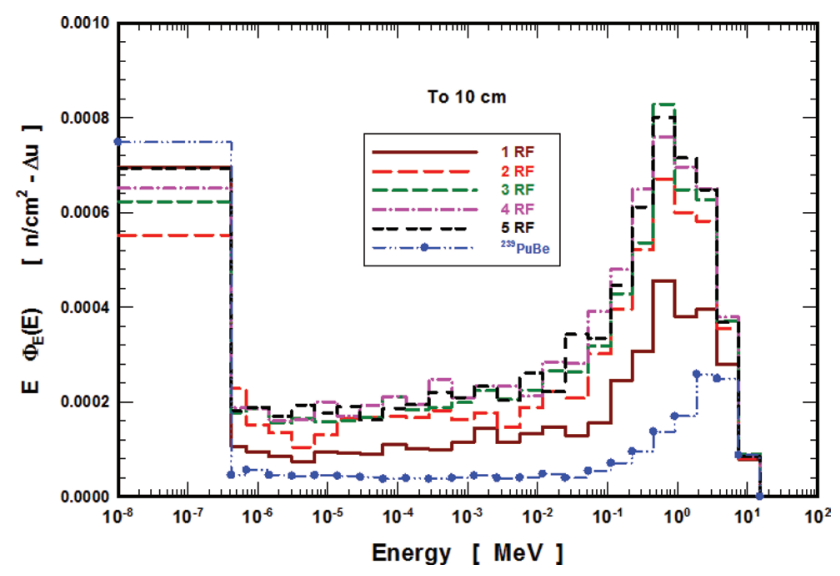

Figure 3: Neutron spectra, per history, to $10 \mathrm{~cm}$ from the center

In figure 4 the neutron spectra are to $20 \mathrm{~cm}$-radius this is inside the third fuel ring. To $20 \mathrm{~cm}$ neutron spectrum due to bare ${ }^{239} \mathrm{PuBe}$ is similar to the neutron spectrum when the reactor has $1 \mathrm{RF}$ for neutrons whose energy is larger to 0.4 $\mathrm{eV}$, but thermal neutron group is larger when the reactor has 1 RF. With 2 RF the amount of thermal neutrons is larger in comparison to reactor with $1,3,4$, and 5 RF.

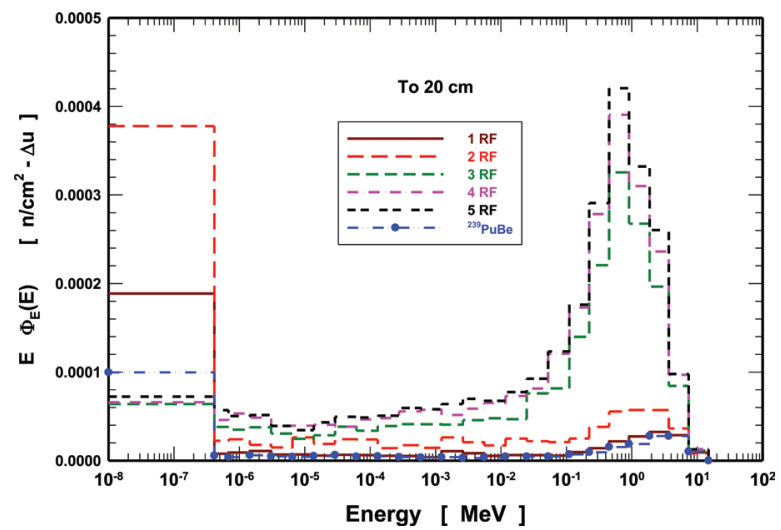

Figure 4: Neutron spectra, per history, to $20 \mathrm{~cm}$ from the center

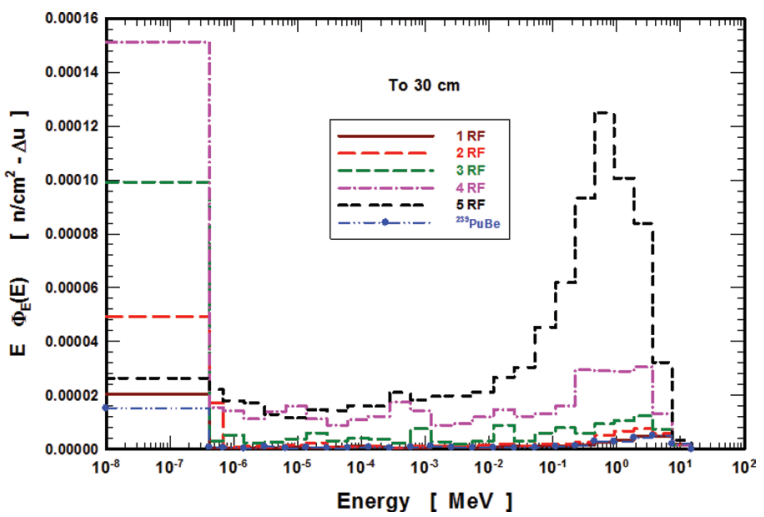

Figure 5: Neutron spectra, per history, to $30 \mathrm{~cm}$ from the center
Neutron spectra to $30 \mathrm{~cm}$, which is located inside the fifth fuel ring, are shown in figure 5. In this point the amount of thermal neutrons is the largest for all cases but when the fifth RF is included, in this case the largest contribution is due fast neutrons probably due to the amount of neutrons produced during fission.

The fifth RF has a radius of $32.5 \mathrm{~cm}$, and the reactor radius is $50 \mathrm{~cm}$, the space from $32.5 \mathrm{~cm}$ to $50 \mathrm{~cm}$ is filled with water. Neutron spectra to $40 \mathrm{~cm}$, which is in the moderator, are shown in figure 6. In this point the main contribution are thermal neutrons where the amount is increased as the fuel rings are added. The reduction of fast neutrons and the increase of thermal neutrons as the distance is increased are similar to measurements carried out in a Nuclear Chicago model 9000 subcritical reactor [22], and a subcritical reactor with TRIGA reactor fuel [23].

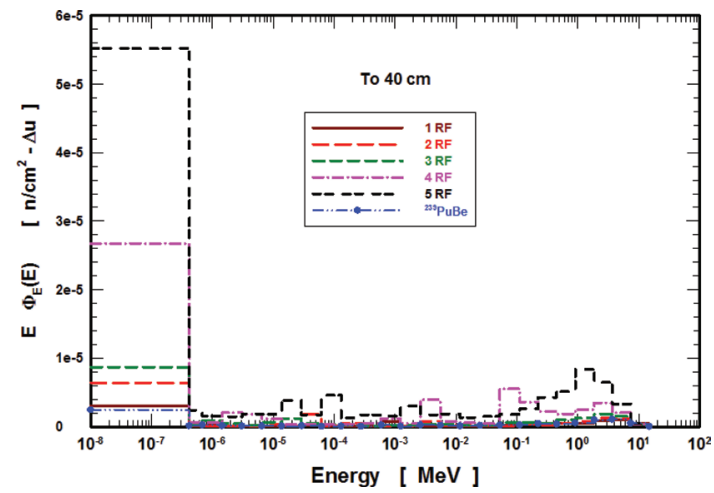

Figure 6: Neutron spectra, per history, to $40 \mathrm{~cm}$ from the center

In the middle point of reactor height total neutron fluence was calculated, in figure 7 is shown the neutron distribution when the reactor has the neutron source and the first fuel ring.

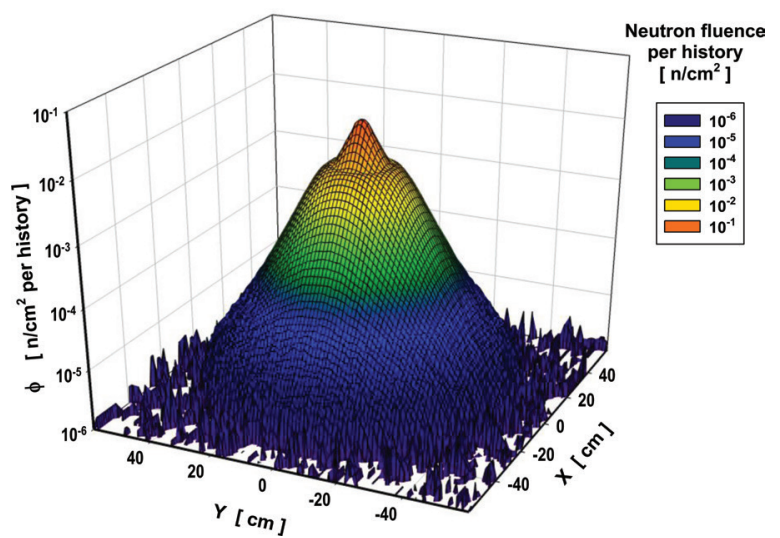

Figure 7: Neutron fluence distribution for reactor with 1 RF

In figures $8,9,10$, and 12 is the neutron distribution for 2 , 3,4 , and $5 \mathrm{RF}$ reactor. In all cases the amount of neutron is small outside the reactor $(51 \mathrm{~cm})$. The neutron distribution is strongly affected by the amount of fuel rings in the reactor. 


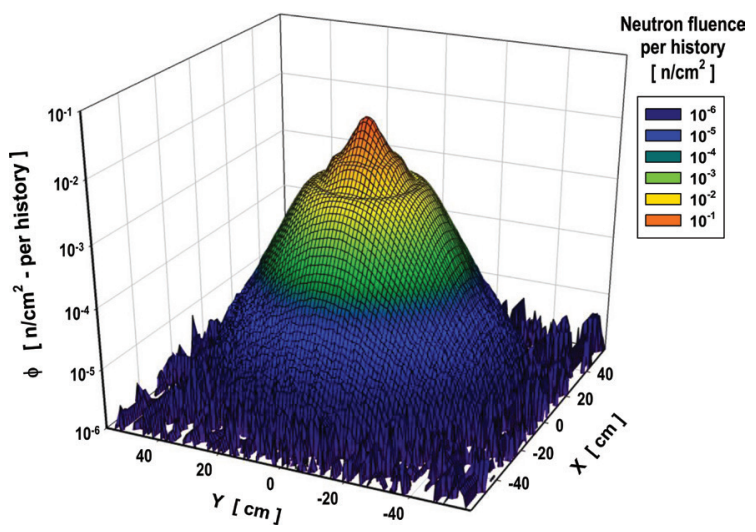

Figure 8: Neutron fluence distribution for reactor with 2 RF

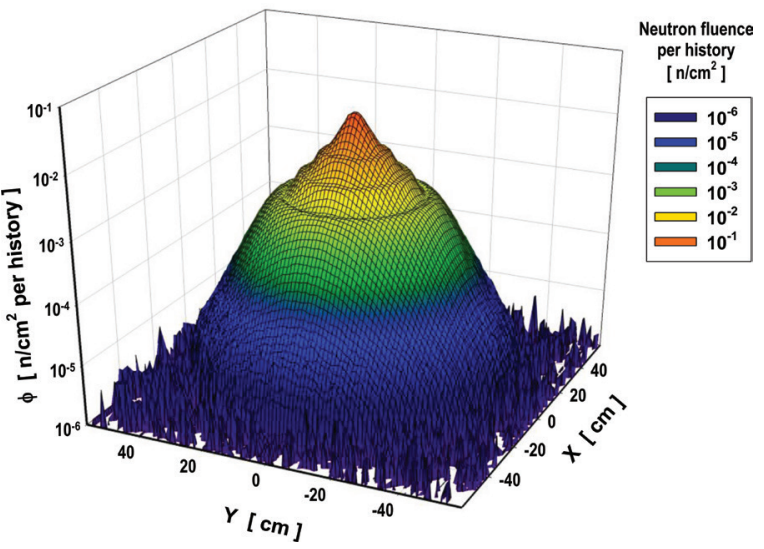

Figure 9: Neutron fluence distribution for reactor with 3 RF

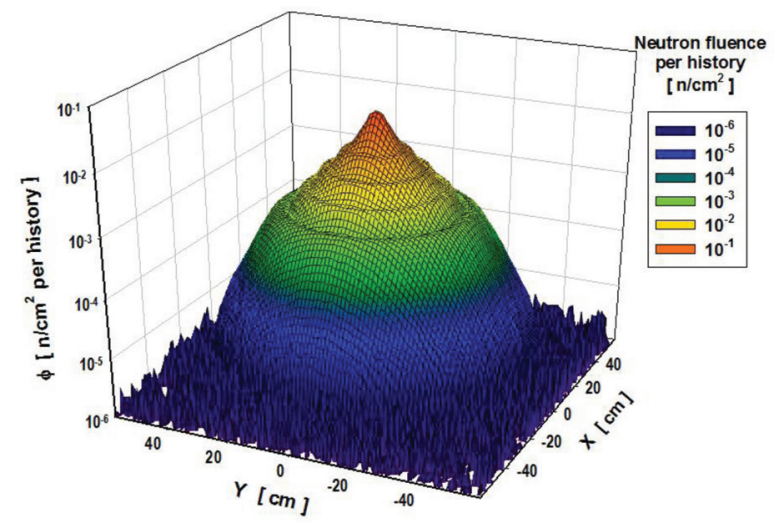

Figure 10: Neutron fluence distribution for reactor with 4 RF

In figures 7, 8, 9, 10 and 11 the distribution of neutron fluence per history are shown for mini subcritical reactor with $1,2,3,4$, and 5 fuel rings, the shape of neutron fluence distribution is alike to the distribution reported for the Jordan subcritical reactor [24]. As the rings of fuel are added the neutron distribution is enhanced due to neutrons produced during fission. In any point in the reactor the neutron fluence is the results of neutrons produced by fission that are transported less those neutrons that leak out from the reactor and those absorbed by the fuel and the moderator.

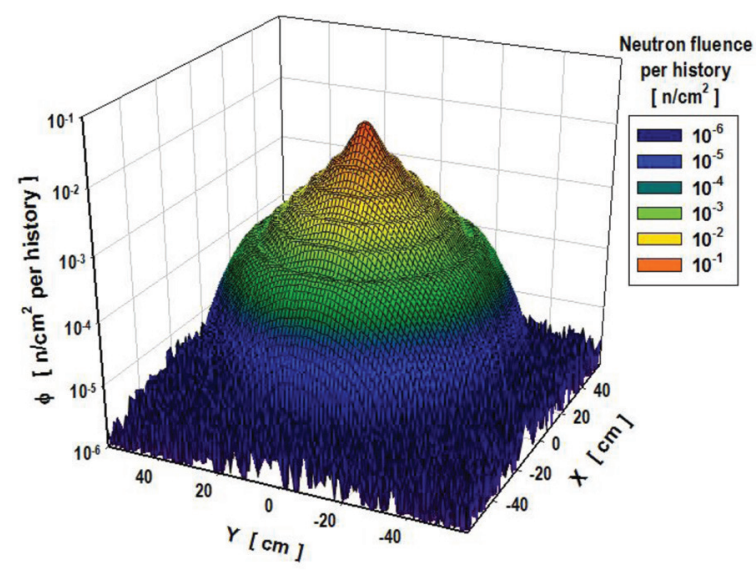

Figure 11: Neutron fluence distribution for reactor with $5 \mathrm{RF}$.

\section{Conclusions}

Monte Carlo methods were used to design a mini subcritical nuclear reactor. This reactor has a ${ }^{239} \mathrm{PuBe}$ isotopic neutron source and has light water as moderator. The reactor is heterogeneous where the fuel is cylindrical rings. In the design five reactors were calculated using $1,2,3,4$, and 5 fuel rings. The $k_{\text {eff }}, \mu$, the reactor power and the ambient dose equivalent rate were calculated, as well as the neutron spectra and the neutron distribution. The features of reactor with 5 rings of fuel were compared with a Nuclear Chicago subcritical nuclear reactor.

All mini subcritical nuclear reactors have a $\mathrm{k}_{\text {eff }}$ less than 1 , ranging from 0.5298 to 0.7819 , the increase of $\mathrm{k}_{\mathrm{eff}}$ is due the increase of fuel mass [25].

Neutron spectra have thermal, epithermal and fast neutrons. The amount of neutrons for each energy group depends upon the site where the spectrum is calculated.

Near the neutron source the amount of fast neutrons is larger than thermal neutrons, as the distance is increased the amount of thermal neutrons is increased.

Neutron fluence distribution tends to enhance as the amount of rings of fuel are added.

Considering the volume and fuel mass of mini subcritical nuclear reactor with 5 rings of fuel in comparison to volume and fuel mass of a Nuclear Chicago subcritical reactor the difference of $\mathrm{k}_{\mathrm{eff}}$ is small.

\section{References}

[1] L. Geng, T. Liu, K. Zhou, G. Yang, G. Energy Policy 113, 87 (2018). 
[2] O. Yue, J. He, S. Zhi, H. Dong, Annals Nuclear Energy 111, 635 (2018).

[3] S. Suman, Journal of Cleaner Production 181, 166 (2018).

[4] M. Abu-Khander, M. Marden, Progress in Nuclear Energy 51, 225 (2009).

[5] N. Nifenecker, S. David, J. Loiseaux, O. Meplan, Nuclear Instruments and Methods in Physics Research A 463, 428 (2001).

[6] F- Faghihia, S. Mirvakili, Nuclear Engineering and Design 239, 1000 (2009).

[7] H. R. Vega-Carrillo, I.R. Esparza-Garcia, A. Sanchez, Annals of Nuclear Energy 75, 101 (2015).

[8] M. Salvatores, I. Slessarev, V. Berthou, Progress in Nuclear Energy 38, 167 (2001).

[9] W.M. Schikorr, Nuclear Engineering and Design, 210, 95 (2001).

[10] G. Stange, T. Mackie, M.A. Corradini, Journal of Radioanalytical and Nuclear Chemistry 305, 23 (2015).

[11] A. Nuttin, D. Heuer, A. Billebaud, R. Brissot, C. Le Brun, Progress in Nuclear Energy 46, 77 (2005).

[12] L. X. González-Puin, H. R. Vega-Carrillo, S. A. Martinez-Ovalle, Rev. Cien. Des. 4, 7 (2014).

[13] S. Kamalpour, H. Khalafi, S.M. Mirvakili, Progress Nuclear Energy 73, 107 (2014).

[14] H.R. Vega-Carrillo, Teoría de Reactores Nucleares (Editorial Académica Española, Saarbrucken, Germany, 2012).
[15] A. Lafuente, M. Piera, Annals of Nuclear Energy 38, 910 (2011).

[16] H. R. Vega-Carrillo, V. M. Hernández-Dávila, T. Rivera, A. Sánchez, Radiation Physics and Chemistry 95, 122 (2014).

[17] Y. Gohar, D. L. Smith, Report ANL-10/05, Argonne National Laboratory (2010).

[18] S. Dawahra, K. Khattab, G. Saba, Annals of Nuclear Energy 63, 594 (2014).

[19] V. Gulik, V. A.H. Tkaczyk, Nuclear Engineering and Design 270, 133 (2014).

[20] X-5 Monte Carlo team, LA-UR-03-1987, Los Alamos National Laboratory (2003).

[21] ICRP, Ann. ICRP 26, 199 (1996).

[22] P. Koseoglou, E. Vagena, S. Stoulos, M. Manolopoulou, Radiation Effects and Defects in Solids 171, 766 (2016).

[23] A. Asuncion-Astronomo, Z. Stancar, T. Goricanec, L. Snoj, Nuclear Engineering and Technology, https://doi.org/10.1016/j.net.2018.09.025. (2018).

[24] M.I. Radaideh, I. Jarrah, S. Malkawi, A. Khateeb, I. Al-Issa, Progress in Nuclear Energy 108, 43 (2018).

[25] L. P. Tucker, S. Usman, A. Alajo, A. Nuclear Technology 194, 97 (2016). 


\section{Journal of Nuclear Physics, Material Sciences, Radiation and Applications}

Chitkara University, Saraswati Kendra, SCO 160-161, Sector 9-C, Chandigarh, 160009, India

Volume 6, Issue 2

February 2019

ISSN 2321-8649

Copyright: [C 2019 Hector Rene Vega-Carrillo et al.] This is an Open Access article published in Journal of Nuclear Physics, Material Sciences, Radiation and Applications (J. Nucl. Phy. Mat. Sci. Rad. A.) by Chitkara University Publications. It is published with a Creative Commons Attribution- CC-BY 4.0 International License. This license permits unrestricted use, distribution, and reproduction in any medium, provided the original author and source are credited. 